\section{Consumers' perception and knowledge of food safety: results of questionnaires accessible on IZSalimenTO website}

\author{
Amaranta Traversa, ${ }^{1}$ \\ Daniela Manila Bianchi, ${ }^{1}$ Sara Astegiano, ${ }^{1}$ \\ Antonio Barbaro, ${ }^{2}$ Maria Cristina Bona, ${ }^{2}$ \\ Elisa Baioni, ${ }^{2}$ Francesca Rubinetti, ${ }^{2}$ Enrico \\ Aliberti, ${ }^{3}$ Carlo Palazzo, ${ }^{3}$ Silvia Gallina, ${ }^{1}$ \\ Lucia Decastelli ${ }^{1}$ \\ 'Food Control and Production Hygiene \\ Unit, Institute for Experimental \\ Veterinary Medicine of Piedmont, Liguria \\ and Aosta Valley, Turin; \\ ${ }^{2}$ Epidemiology Unit, Institute for \\ Experimental Veterinary Medicine of \\ Piedmont, Liguria and Aosta Valley, \\ Turin; \\ ${ }^{3}$ Informatic and Telematic Unit, Institute \\ for Experimental Veterinary Medicine of \\ Piedmont, Liguria and Aosta Valley, \\ Turin, Italy
}

\section{Abstract}

The present survey was undertaken to investigate consumers' knowledge of the main foodborne agents and dietary regimen during pregnancy. Data were collected using monthly questionnaires available on IZSalimenT0 website between March 2013 and January 2014. Hepatitis A virus questionnaire: 20 respondents (77\%) recognized berries as foodstuff linked to the outbreak of hepatitis A. The majority correctly indicated as precautionary advice to boil berries before consumption. Botulism questionnaire: 29 respondents (62\%) indicated pesto as food involved in botulism alert in July 2013. The risk of infant botulism in infant less than 1 year old due to honey consumption is known by 24 respondents (51\%). Main foodborne disease questionnaire: the risk of infection by Salmonella after the consumption of foods made with raw eggs is known by the majority $(94 \% ; \mathrm{N}=17)$ as well as the treatments to be applied in order to make fresh fish safe from parasites (76\%). Pregnancy questionnaire: 20 respondents (74\%) believed that washing vegetables and fruits with sodium bicarbonate or chlorate solution is able to inactivate Toxoplasma; only $4(15 \%)$ reported both raw meat and vegetables washed with sodium bicarbonate as food at risk. Results indicate that all consumers should be trained on behaviour and dietary regimen to be adopted in pregnancy and in infant $<1$ year old. The website may be consid- ered as a useful tool to assess consumers' knowledge: both the news section and the contents published may be a source of information and education for consumers on food safety.

\section{Introduction}

A total of 763 strong-evidence foodborne outbreaks were reported in European Union (EU) in $2012 ; 39.7 \%$ of these occurred in household kitchen (European Food Safety Authority, 2014). Understanding consumers' awareness regarding home food safety and preparation practices is essential to plan proper education programmes. Many studies have investigated consumers' perception of food safety and of related risks, and many authors reported that consumers demonstrated judgements of it won't happen to me, illusion of control and illusion of relative invulnerability to food poisoning from self-prepared food (Redmond and Griffith, 2004; McCarthy et al., 2007).

According to the survey carried out by the European Commission among the EU citizens, the majority of respondents associate food and eating with pleasure. Food safety is less commonly associated with foodstuff and eating: when offered a list of possible issues associated with food, few respondents are worried about environmental pollutants and bacteria contaminations (European Commission, 2010). The survey underlines that most respondents keep their behaviour or ignore information when hearing something about unsafe or unhealthy food. The most common reaction is to temporarily avoid food mentioned in the alert, especially when information is related to food safety: only about one out of ten respondents stated they had permanently changed their eating habits (European Commission, 2010).

The present survey was undertaken to investigate the consumers' knowledge of food safety and hygiene throughout users' filling in of the questionnaires available on IZSalimenTO website and to assess the use of this website as a tool to evaluate users' knowledge. Information about the main foodborne agents, the outbreaks and the dietary regimen to be adopted during pregnancy were collected.

\section{Materials and Methods}

Data were collected using questionnaires available on IZSalimenT0 website (http://www.izsalimento.izsto.it/palimenti/) in the period March 2013 - January 2014. IZSalimenT0 is a website on food safety created and edited by the Institute for Experimental Veterinary Medicine of Piedmont, Liguria and Aosta Valley during a
Correspondence: Amaranta Traversa, Food Control and Production Hygiene Unit, Institute for Experimental Veterinary Medicine of Piedmont, Liguria and Aosta Valley, via Bologna 148, Turin, Italy.

Tel: +39.011.2686233.

E-mail: amaranta.traversa@izsto.it

Key words: Food safety, Consumer knowledge, Questionnaires.

Conflict of interests: the authors declare no potential conflict of interests.

Funding: the study was funded by the Italian Ministry of Health - Current Research 2010 (Min. Code IZSPLV08/10). The study was partially funded by 5 per thousand funds available for 2009.

Received for publication: 9 July 2014 . Revision received: 24 November 2014. Accepted for publication: 27 November 2014.

This work is licensed under a Creative Commons Attribution 3.0 License (by-nc 3.0).

(C) Copyright A. Traversa et al., 2015

Licensee PAGEPress, Italy

Italian Journal of Food Safety 2015; $4: 4533$

doi:10.4081/ijfs.2015.4533

Research project funded by the Italian Health Ministry. No on-line registration was required by the users to enter the website and the questionnaires were anonymous. Each questionnaire was published online monthly, was available for a month and then was substituted with another one.

Each questionnaire was divided in two sections: the first was designed to propose 5 or 6 multiple choice questions about the item specific to the questionnaire and the second one collected information about demographic characteristics (gender, age, education level and post code). The structure of the questionnaires was worked out in order to propose a quick filling and brief focus on a specific item. At the end of each filling session respondents could read a short pill of wisdom focused on the topics of the questionnaire where the most important concepts and the main points were reported. The right answers to the questionnaires supplemented by a brief explanation were provided on the website at the end of the on line publishing period.

In the considered period we published on line 11 questionnaires. This paper reports the main results about information collected by the most appreciated questionnaires: botulism and food questionnaire, Hepatitis A virus questionnaire, main foodborne disease questionnaire, pregnancy and food safety questionnaire. 


\section{Results}

A total of 191 respondents took part to the survey and filled in the questionnaires available on website. This data comes from the collection of all the responses to the eleven questionnaires published in the website during the period considered. More than three-quarters (78\%) of respondents were female. The age class more involved was 31-45 years (44\%). The age, gender and education level of respondents are shown in Figure 1. The analysis of the geographical location of users shown that the majority (74\%) logged in by Piedmont, $21 \%$ by other Italian regions, and the remaining $5 \%$ outside Italy. The respondents' knowledge about food safety dealing with the four questionnaires considered in the survey is shown in the Appendix; the main results are reported below.

\section{Hepatitis A virus questionnaire}

In November 2013 a questionnaire dedicated to Hepatitis A virus outbreak was published on the website, 20 respondents (77\%) recognized frozen berries as foodstuff linked to the outbreak of Hepatitis A, 19\% indicated shellfish, and $4 \%$ pesto. Precautionary advice to boil frozen berries before consumption was selected by 22 respondents (84\%) followed by other advices as to freeze within 24 hours (12\%) and to vacuum package (4\%).

\section{Botulism and food questionnaire}

Twenty-nine respondents (62\%) identified the correct food matrix involved in the botulism alert in pesto occurred in July 2013, other foodstuff as tinned tomatoes and berries was selected by $38 \%$. The majority of users knew that Clostridium botulinum is a bacterium (94\%), as well as that this microorganism may especially be present in low acid home-canned food (89\%) and that bacteria and toxins are not inactivated by freezing (75\%). To the specific question about which kind of food had not to be given to an infant under 1 year of age because of the risk of infant botulism, 24 respondents (51\%) selected honey, followed by eggs (34\%) and cow's milk (15\%). Moreover, in the main foodborne disease questionnaire 13 users (76\%) indicated honey as food in which people must avoid to dip baby's pacifier for infant botulism risk; pasteurized fruit juice was chosen by $12 \%$ of users, banana milkshake by $6 \%$ and sugar by $6 \%$.

\section{Main foodborne disease questionnaire}

Sixteen respondents (94\%) correctly identified tiramisu and homemade mayonnaise as foods at risk for Salmonella, $6 \%$ selected the roast veal and the baked ham. Thirteen respondents (76\%) selected correctly the advice to freeze to a temperature of $-20^{\circ} \mathrm{C}$ within
24 hours and to deep cook to a temperature not less than $60^{\circ} \mathrm{C}$ as the treatments to be applied in order to make fresh fish safe from parasites. Three respondents (18\%) indicated the freezing to a temperature of $-20^{\circ} \mathrm{C}$ within 12 hours and 1 respondent (6\%) the drying.

\section{Pregnancy and food safety questionnaire}

Twenty respondents (74\%) believed that washing vegetables and fruits with sodium bicarbonate or chlorate solution is able to inactivate Toxoplasma. Moreover, to the question about which foodstuff can be considered at risk for Toxoplasma, $82 \%$ indicated the raw meat, $15 \%$ reported both raw meat and vegetables washed with sodium bicarbonate and the last $3 \%$ both mortadella and the raw meat. On the other hand, dealing with the cheese dietary regimen to avoid in pregnancy, raw milk cheese was selected by $59 \%$ of users, blue cheese by $19 \%$, both cheeses by $11 \%$ and pasteurized milk cheese by the last $11 \%$.

\section{Discussion}

Our survey evaluate food safety knowledge among IZSalimenTO website users using on line anonymous questionnaires. Research methods that rely on website tools has a sample selection bias: the respondents to the on line questionnaires are a non random-sampled of consumers because they represent a part of the population (web users, interested in food safety). Despite this sampling bias, the information obtained in the study may be useful to evaluate consumers knowledge about food safety and to plan proper educational programs.

In the questionnaire dedicated to hepatitis A virus outbreak, the great majority of consumers seem to be aware about the outbreak and the precautionary treatment to be used before consumption of frozen berries; this probably is due to the prolonged hepatitis A outbreak and the presence of many new cases of infection in Italy that let the consumers to be informed.

Two months later the botulism alert occurred in July 2013, less than half respondents recognized pesto as the food matrix involved; the majority indicated foodstuff involved in others outbreaks. A large majority of consumers seemed to be familiar with the bacterium responsible of botulism and the main food that may be involved in Clostridium botulinum infections. However, the risk of infant botulism in children less than 1 year old due to honey consumption is little known: about half of respondents identified honey while the remaining users indicated eggs and cow's milk, food matrices that a child under 1 aged had not to consume for nutritional reasons. However, the majority of users that filled the main foodborne disease questionnaire correctly indicated that dip pacifier in honey is not advisable.

According to the responses to the questionnaire dealing with the main foodborne agents, three-quarters of users known the risk of infection by Salmonella after the consumption of foods made with raw eggs as well as the treatments to be applied in order to make fresh fish safe from parasites.

About dietary regimen to be adopted in pregnancy, three-quarters of respondents believed

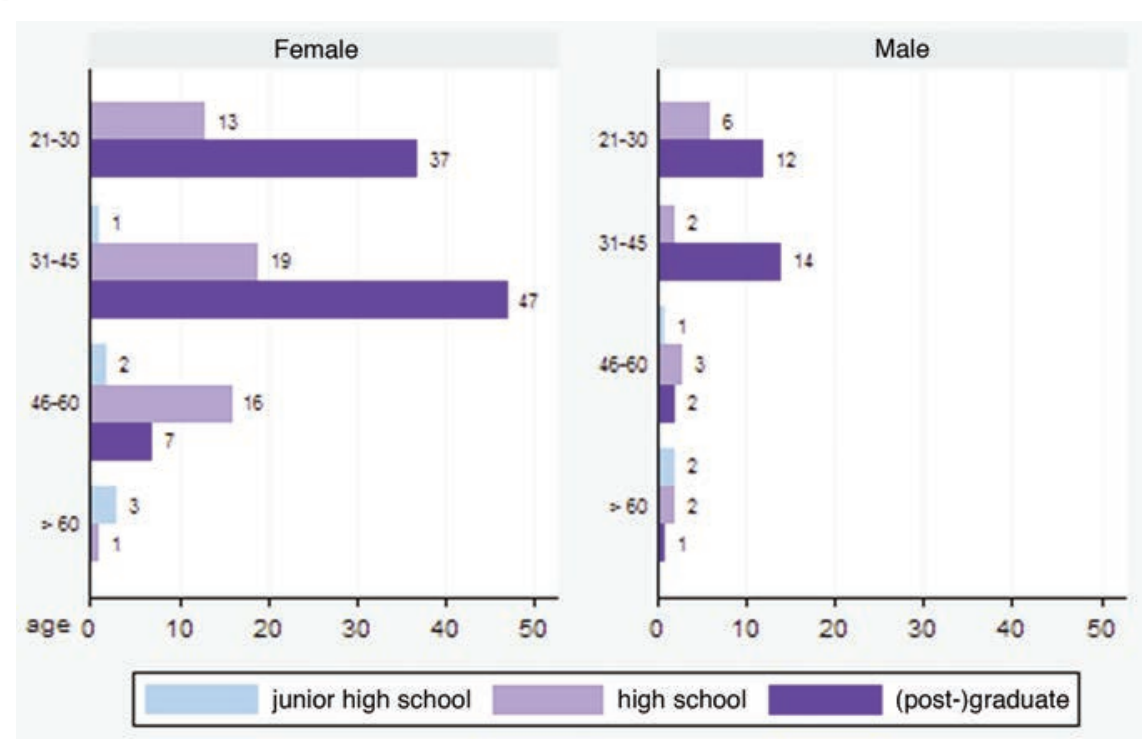

Figure 1. Distribution of total respondents $(\mathrm{N}=191)$ by gender, age class and education level (graduate and post-graduate were grouped together). Values are expressed as percentage. 
that washing vegetables and fruits with sodium bicarbonate or chlorate solution is able to inactivate Toxoplasma. Moreover, only 15\% reported both raw meat and vegetables washed with sodium bicarbonate as foods at risk for Toxoplasma. These findings underline that the majority of respondents were not aware that the washing treatment of raw vegetables and fruits with chlorate solution or sodium bicarbonate are not able to make these foodstuff safe from Toxoplasma. Dealing with cheeses that are not recommended to be consumed during pregnancy, only a small portion of users selected both raw milk and blue cheese. Probably raw milk and derived products were better known thanks to the widespread Italian system to retail raw milk through vending machine.

Many studies used different methods, study designs and scopes to investigate consumers' food safety perceptions, knowledge and behaviour, creating difficulties in making comparison. Consumers' knowledge was assessed by several authors worldwide. A good general awareness of food safety was reported among Canadian consumers (Nesbitt et al., 2014). In Ireland, the majority knew what it should be done when preparing and handling food, but in many cases an ideological position may have influenced consumers' response more than knowledge (McCarthy et al., 2007). Among US Hispanic families, an high self confidence in preparing safe food was reported despite little knowledge of safe food handling (Stenger et $a l ., 2014)$. In Italy, the great majority of respondents showed a positive attitudes towards foodborne disease prevention and control but revealed a lack of knowledge of main foodborne pathogens (Angelillo et al., 2001).
As reported by McCarthy et al. (2007), we need to focus food education strategies especially on groups at risk and we also need to understand the reasons why the adoption of less than ideal practice is regarded as safe.

\section{Conclusions}

Information collected via the website shows that users were fairly involved in food safety topics dealt in the questionnaires. Data underline the need to enlarge consumers' knowledge of food safety with specific technical skill. The dietary regimen to be adopted towards sensitive people, as pregnant and infants under one year of age, should be subject of training and education activities to address to all consumers. The majority of respondents were aware of the main points about the foodborne outbreak considered in this survey. Although website users represent a part of consumers population, the website may be considered as a useful tool to assess consumers' knowledge using the questionnaires section. Simultaneously, both the news section and the contents published on the website may be a source of education and training for the consumers about food safety. As reported by Nesbitt et al. (2014), the internet and social media appeared to be the best method to reach audience for food safety education. IZSalimenT0 website may be a useful tool to collect information about consumers, to estimate users' food safety knowledge and to provide contents in order to inform and educate consumers about food safety.

\section{References}

Angelillo IF, Foresta MR, Scozzafava C, Pavia $\mathrm{M}, 2001$. Consumers and foodborne disease: knowledge, attitudes and reported behavior in one region of Italy. Int $\mathbf{J}$ Food Microb 64:161-6.

European Commission, 2010. Food-related risks. Report. TNS Opinion \& Social ed., Brussels, Belgium.

European Food Safety Authority, 2014. The European Union summary report on trends and sources of zoonoses, zoonotic agents and food-borne outbreaks in 2012. EFSA J 2014 12:3547.

McCarthy M, Brennan M, Kelly AL, Ritson C, de Boer M, Thompson N, 2007. Who is at risk and what do they know? Segmenting a population on their food safety knowledge. Food Qual Prefer 18:205-17.

Nesbitt A, Thomas MK, Marshall B, Snedeker K, Meleta K, Watson B, Bienefeld M, 2014. Baseline for consumers food safety knowledge and behaviour in Canada. Food Control 38:157-73.

Redmond EC, Griffith CJ, 2004. Consumer perceptions of food safety risk, control and responsibility. Appetite 43:309-13.

Stenger KM, Ritter-Gooder PK, Perry C, Albrecht JA, 2014. A mixed methods study of food safety knowledge, practices and beliefs in Hispanic families with young children. Appetite 83:194-201. 